\title{
COCKPIT CRISES AND DECISION MAKING: IMPLICATIONS FOR PILOT TRAINING
}

\author{
Dr. Maureen A. Pettitt \\ California State University
}

\begin{abstract}
This paper presents the theoretical foundations and a description of a research study designed to examine pilots' attitudes about cockpit crises and the processes used to make decisions in crises. The findings suggest that a "high crisis perception/low urgency/low rigidity" pattern may be an optimal approach to crisis decision making. In other words, the decision maker recognizes the situation as a crisis and is motivated to act, but the low sense of urgency encourages flexibility with respect to roles, responsibility, participation, and procedures. Suggestions for both ground training and simulator instruction are offered which expand situational awareness to include the concepts of crisis and available decision time.
\end{abstract}

\section{Introduction}

Crisis situations in the cockpit occur in a relatively complex, often ambiguous, sometimes hostile environment. However, the high achievement and task orientations of crew members seem to produce optimal responses in most situations that would be described as crises. Extensive technical training and highly structured emergency procedures provide pilots a means for diagnosing and responding to critical situations. Nevertheless, the history of commercial aviation is marred with many accounts of mismanaged crises.

The aviation community has long realized that the effective performance of cockpit crews is essential to aviation system safety. Early research in the area of flight crew performance focused primarily on skills acquisition and retention, perceptual requirements, and physical stress. Much less attention was given to the psychosocial aspects of the cockpit environment. Air transport accident analyses and related research during the past decade have, however, produced convincing evidence that pilot training and evaluation systems must address the crucial dimension of crew interaction and decision making in the cockpit (Foushee 1984; Ruffell Smith 1979; Sears 1986; Wheale 1984).

In recent years many airlines have initiated training programs to encourage effective cockpit resources management (CRM). Although CRM programs vary, they are essentially designed to educate pilots (and, more recently, cabin and ground crews) about the importance of interpersonal relations, communication skills, synergistic activity, and participatory decision making to safe flight operations--training quite in contrast to the traditional focus on the technical means of accomplishing the goals of flight operations rather than the process.

Subsequent, evaluative research has supported the notion that CRM training can improve cockpit performance and, further, suggests that performance-related attitudes are significant predictors of crew coordination in line operations (Helmreich, Foushee, Benson, and Russini 1986). However, research 
also indicates that crewmembers lack awareness of the deleterious effects of stress and have unrealistic attitudes about their personal vulnerability to stress (Helmreich 1984). Some researchers caution that during a crisis situation the crew is likely to revert to prior well-learned behaviors rather than the concepts espoused by CRM (Hackman 1987b).

It is expected, however, that over a period of time CRM training--if an accepted and customary component of initial and recurrent training programs--will encourage behaviors which lead to more effective coordination and decision making in critical or crisis situations (Hackman 1987b; Helmreich 1984; Helmreich and Wilhelm 1987).

\section{Crisis and Group Decision Making}

A crisis is triggered by incremental or radical changes in the environment. A crisis threatens the goals of the decision unit and involves risks with the potential for substantial losses. There is a relatively short time in which to make a decision before loss occurs. The crisis is further exacerbated by the lack of a contingency plan and of decision-relevant information. Not surprisingly, the psychological and physiological manifestations of stress accompany the crisis situation. In sum, the crisis situation is characterized by threat, uncertainty, limited information, time pressure and tension (Billings, Milburn and Schaalman 1980; Hermann 1969; Milburn 1972; Miller 1963; Staw, Sanderlands and Dutton 1981).

The psychological and physiological responses to crisis as well as individual differences in personality predispositions and perceptions affect the processes employed by the group, and, ultimately, decision outcomes. The evidence suggests that individual cognitive flexibility is restricted in a crisis. Decision makers may overemphasize similarities between the past and the present (Milburn 1972), gravitate toward simple decision rules (Janis and Mann 1977; Nagel 1988), rely on well-learned, dominant behavior (Zajonc 1965), suffer from a foreshortened time perspective (Milburn 1972) and be indiscriminate in the search for information or, conversely, ignore relevant information (Janis and Mann 1977).

In addition, the strategies utilized by the crew and the control structures within which decisions are made are determined to varying degrees by leadership--the leader's abilities, style, influence, and orientations toward the task and relational aspects of group performance. The evidence suggests that, in a crisis, leaders often tend to restrict information, participation and shared responsibility. These strategies are designed to reduce error, losses, and uncertainty and to encourage quick and decisive action. However, such strategies often result in information overload, omission, or distortion; role overload; and reducing the number of decision participants (Billings, Milburn and Schaalman 1980; Dutton 1986; Smart and Vertinsky 1977; Staw, Sanderlands and Dutton 1981).

Alternatively, decision making is likely to be more successful in cockpit crises if (1) group norms encourage shared information and responsibility for decision making (Foushee 1984; Foushee and Helmreich 1988); (2) the crew has confidence that a satisfactory solution exists and believes that there is sufficient time available to search for and evaluate alternative courses of action (Janis and Mann 1977); (3) the crew evaluates and utilizes available resources to develop alternatives, strategies or new resources, rather than relying upon existing strategies and resources to resolve the situation (Hackman 1987a); and (4) individuals are trained for cognitive flexibility under adverse conditions (Dutton 1981). 


\section{Description of the Research}

The purpose of the study was to examine pilots' perceptions about three constructs central to decision making in cockpit crisis situations--the perception of crisis, sense of urgency, and response rigidity. The survey materials included a crisis scenario, a two-part, nineteen-item questionnaire and a background information sheet. The scenario and questionnaire items had been pre-tested during personal interviews conducted with twenty-four Denver-based line pilots employed by a major airline.

Subjects. The subjects of the study were Los Angeles-based line pilots from three major airlines. Six hundred and fifty-seven surveys were distributed. One hundred and eighty-five usable surveys were returned and used in the analysis. The subjects represented a relatively broad cross-section of the pilot population (i.e., $46 \%$ were captains, $33.5 \%$ were first officers, and $20 \%$ were second officers; $38 \%$ were not yet forty years old, the other 62 were; $67 \%$ had no formal CRM training while the other $33 \%$ had).

The concept of crisis was measured in two ways. The perception of crisis was determined by asking pilots if they believed that this crew was in crisis situation (Question 1, Part I). They were asked to respond on a Likert-type scale numbered 1 (strongly agree) through 7 (strongly disagree). In Part II of the questionnaire pilots were asked to rate five crisis characteristics of the scenario on a Likert-type scale numbered 1 (low) to 9 (high). The second measure of crisis is a combination of the mean ratings of four crisis characteristics-level of threat to the safety of the flight, level of situational uncertainty, availability of decision-relevant information, and the level of tension.

The perception of urgency--the perceived time available in which to search for and evaluate alternative courses of action--was measured by combining the responses to three questions in Part I in addition to the rating of the fifth crisis characteristic, level of time pressure, in Part II of the questionnaire.

Response rigidity is characterized by the restriction of participation, limiting the search for and evaluation of viable alternatives, and adherence to/reliance on authority and procedures. Nine questions in Part I of the questionnaire were used to determine response rigidity.

It was hypothesized that (1) the perception of crisis would have a positive correlation to the ratings of the crisis characteristics, (2) the higher the rating of the situation as a crisis, the higher the response rigidity, and (3) a high sense of urgency would result in high rigidity.

\section{Results of the Study}

Ninety percent of the pilots surveyed indicated, at some level of agreement, that the crew in the scenario was in a crisis situation. This crisis perception positively correlated with their ratings of the level of threat, uncertainty, information availability and tension--characteristics commonly attributed to crisis situations.

It was anticipated that the effects of the pilot personality, hierarchical task/role structures in the cockpit, and pilot training procedures--which have, traditionally, emphasized individual, mechanistic responses to emergencies- would lead to a high response rigidity when the perception of crisis was high. Response rigidity is characterized by reluctance to engage in participatory decision making or to search for and evaluate alternative courses of action, and reliance on the captain's capabilities, deference to his or her authority, and reliance on standard operating procedures. 
The hypothesis that a higher perception of crisis would result in higher response rigidity was not supported by the data. The results indicated that a higher perception of crisis resulted in a lower rigidity score $(r=-.18)$. Further, pilots had, overall, a lower rigidity score than expected.

It was also expected that a higher sense of urgency would result in higher response rigidity. Previous studies of decision making suggest that a high sense of urgency (the belief that there is little time to search for and evaluate alternative courses of action) may evoke dysfunctional decision making behavior characterized by the restriction of information, authority, and participation. The hypothesis that high urgency would result in high response rigidity was supported by the data. The higher the sense of urgency the higher the response rigidity $(r=.25)$.

The findings indicate that the perception of crisis and response rigidity are negatively related (high crisis/low rigidity, low crisis/high rigidity) and the sense of urgency and response rigidity are positively related (low urgency/low rigidity, high urgency/high rigidity). Rigidity scores were not significantly different as a result of a high or low perception of crisis, however, pilots with a low sense of urgency had significantly lower rigidity scores than pilots with a high sense of urgency. These results suggest the interpretation that sense of urgency-the time component of crisis--drives decision making behavior, more so than the perception of crisis.

While the results of this study were not conclusive, they strongly suggest the possibility that the high crisis perception/low urgency/low rigidity pattern may be an optimal approach to crisis decision making. First, the decision maker recognizes the situation as a crisis. As a result of this awareness the decision maker experiences mild but "helpful" stress and is, consequently, motivated to act on the situation. The low sense of urgency-the belief that there is sufficient time to search for and evaluate alternative courses of action-encourages flexibility with respect to roles, responsibility, participation, and procedures.

Conversely, pilots exhibiting the high crisis/high urgency/high rigidity pattern may be behaviorally similar to people who suffer from the high, debilitating stress which ultimately inhibits performance. They may resemble the hypervigilant decision maker described by Janis and Mann (1977) whose high arousal state results in impaired cognitive functioning and narrowed time perspectives. The study similarly suggests (although less conclusively) that a high, or at least moderate, perception of crisis is antecedent to the low urgency/low rigidity response pattern. The present research makes a stronger case for low sense of urgency as antecedent to flexible, participatory decision making.

\section{Implications for Pilot Training}

The research lends additional support to the findings that cockpit resource management training improves attitudes toward crew coordination and decision making (e.g., Helmreich 1989). Pilots who had attended formal CRM training programs exhibited a significantly lower sense of urgency and significantly lower response rigidity than pilots who had no formal CRM training.

The results of this study also provide some possibilities for expanding or modifying content in pilot training programs in industry and those used in colleges and universities. While there are implications for several concepts central to most CRM training programs--decision making, communication, stress management (U.S. Federal Aviation Administration 1989)--the concept of situational awareness is most relevant to the present discussion. 
It has been argued that an accurate assessment of crisis is a necessary first step toward crisis resolution (Billings, Milburn and Schaalman 1980). In aviation, this notion is embodied in the concept of situational awareness. Situational awareness is generally considered to be the accurate perception of the factors and conditions that affect the aircraft. In other words, a pilot who is situationally aware has made an accurate assessment of reality. However, the concept of situational awareness as currently conceived focuses primarily on information processing and communication (e.g., Nagel 1988) with little reference to temporal structure or awareness.

The results of this study suggest that it would be beneficial to expand the concept of situational awareness to include (a) the concept of crisis and (b) the accurate assessment of decision time available in critical situations (as opposed to relying on an internally-perceived time frame). Pilots should be aware that in a crisis time perspectives are constricted and short-term goals and consequences tend to be overemphasized.

One means of accomplishing this in a ground training session is the use of the critical incident technique. Flannagan (1954) used this technique successfully in the 1940s to collect observations of flight crew behavior (incidents) which significantly contributed to a specified outcome (were critical). The critical incident technique can be used to sensitize pilots to the importance of an accurate perception of time to situational awareness and informed decision making. For example, the instructor might ask pilots for a factual, detailed account of the behavior of the flight crew in a situation which could be considered--by them or by someone else--a crisis. The resulting list of behaviors could then be categorized along behavioral dimensions normally associated with CRM, but with special emphasis on temporal perceptions and errors. The criteria used to establish the situation as a crisis could be similarly examined.

An expanded concept of situational awareness is applicable to simulator training as well as ground training. Debriefing sessions could include evaluation of how the crew assessed the decision time available, the accuracy of that assessment, and how time perspectives affected the processes used to resolve the crisis. This approach is not limited to the full-motion, high-fidelity simulators utilized by major airlines. Such training might be accomplished just as effectively in low-fidelity simulators or using interactive video workstations and video recordings of behavior (e.g., Foushee and Helmreich 1988).

The roles, the skills, and the training required of pilots are changing. The successful pilot of the next century will advance based not only on technical skills and total experience but on his or her management skills as well. Cockpit resources management is designed, as the name implies, to improve the management of resources in the cockpit. These resources are commonly categorized as people, information, and equipment. The present paper suggests that the concept of time should be added to this list of interrelated resources, especially in critical or crisis situations. Further research is also needed to clarify how patterns of information exchange and processing might encourage the accurate perception of crisis and assessment of decision time. The findings could contribute a great deal to understanding crew performance in crisis situations and provide valuable information relevant to CRM and other pilot training programs. 


\section{References}

Billings, R. S., Milburn, T.W., \& Schaalman, M.l. (1980). Crisis perception: A theoretical and empirical analysis. Administrative Science Quarterly, 25, 300-15.

Dutton, J. E. (1986). The processing of crisis and non-crisis strategic issues. Lournal of Management Studies, 23, 501-517.

Flannagan, J. C. (1954). The critical incident technique. Psychological Bulletin, 51, 327-57.

Foushee, H. C. (1984). Dyads and triads at 35,000 feet. American Psychologist, 39 885-893.

Foushee, H. C., \& Helmreich, R. L. (1988). Group interaction and flight crew performance. In E. L. Wiener \& D. C.Nagel (Eds.). Human factors in aviation (pp. 189-227). San Diego, CA: Academic Press.

Hackman, J. R. (1987a). The design of effective work teams. In J. W. Lorsch (Ed.), Handbook of organizational behavior (pp. 315-342). Englewood, NJ: Prentice-Hall. (1987b). Group level issues in the design and training of cockpit crews. In H. W. Orlady \& H. C. Foushee (Eds.), Cockpit resource management training: Proceedings of the NASA/MAC Workshop (NASA CP-2455) (pp. 23-39). Moffett Field, CA: NASA-Ames Research Center.

Helmreich, R. L. (1984). Cockpit management attitudes. Human Factors, 26, 583-589. . (1989). Evaluating the effectiveness of cockpit resource management training. Washington, D. C.: 1989 Human Error Avoidance Techniques Conference. Photocopied.

Helmreich, R. L., Foushee, H. C., Benson, R., \& Russini, R. (1986). Cockpit management attitudes: Exploring the attitude-performance linkage. Aviation, Space and Environmental Medicine 57 1198-2000.

Helmreich, R. L., \& Wilhelm, J. A. (1987). Evaluating cockpit resource management training. In R. S.Jensen (Ed.),Proceedings of the Fourth International Symposium on Aviation Psychology (pp. 440-446). Columbus, $\mathrm{OH}$ : Ohio State University Department of Aviation.

Hermann, C. F. (1969). Crisis in foreign policy. Indianapolis: Bobbs-Merrill.

Janis, I. L., \& Mann, L. (1977). Decision making: A psychological analysis of conflict, choice, and commitment. New York: The Free Press.

Milburn, T. W. (1972). The management of crisis. In C. F. Hermann (Ed.), International crisis: Insights from human behavioral research (pp. 257-277). New York: The Free Press.

Miller, K. (1963). The concept of crisis. Human Organization, 22, 195-201.

Nagel, D. C. (1988). Human error in aviation operations. In E. L. Wiener \& D. C. Nagel (Eds.), Human factors in aviation (pp. 263-303). San Diego, CA: Academic Press.

Ruffell Smith, H. P. (January, 1979). A simulator study of the interaction of pilot workload with errors, vigilance and decisions (NASA Report TM-78482). Moffett Field, CA: NASA-Ames Research Center.

Sears, R. L. (1986). A new look at accident contribution and the implications of operational and training procedures. Seattle, WA: Boeing Commercial Aircraft Company.

Smart, C., \& Vertinsky, I. (1977). Designs for crisis decision units. Administrative Science Quarterly, 22, 640-657.

Staw, B. M., Sanderlands, L. E., \& Dutton, J. E. (1981).Threat-rigidity effects in organizational behavior: A multi-level analysis. Administrative Science Ouarterly 26 501-524.

U. S. Federal Aviation Administration. (December, 1989). Cockpit Resources Management Training (Advisory Circular 120-51). Washington, D. C.: Federal Aviation Administration.

Wheale, J. L. (1984). An analysis of crew coordination problems in commercial transport aircraft. International Journal of Aviation Safety, 2, 83-89.

Zajonc, R. B. (1965). Social facilitation. Science 149 269-274. 